Jurnal Sains \& Teknologi Modifikasi Cuaca, Vol.20 No.2, 2019: $79-89$

\title{
DETEKSI KEBAKARAN HUTAN DAN LAHAN MENGGUNAKAN CITRA SATELIT HIMAWARI-8 DI KALIMANTAN TENGAH
}

\author{
Forest and Land Fires Detection Using Himawari-8 Satellite Imagery in \\ Central Kalimantan
}

\author{
Alpon Sepriando ${ }^{1,3)^{*}}$, Hartono ${ }^{2)}$, Retnadi Heru Jatmiko ${ }^{2)}$ \\ 1) Program Studi Magister Penginderaan Jauh, Fakultas Geografi, Universitas Gadjah Mada \\ 2) Departemen Sains Informasi Geografi, Fakultas Geografi, Universitas Gadjah Mada \\ 3) Badan Meteorologi Klimatologi dan Geofisika, Jl. Angkasa I No.2 Kemayoran Jakarta Pusat 10720 \\ *E-mail: meteo.go@gmail.com
}

\begin{abstract}
Intisari
Kebakaran hutan dan lahan terjadi hampir setiap tahun di Indonesia, terutama di wilayah Sumatera dan Kalimantan saat musim kemarau. Deteksi kebakaran hutan dan lahan dengan citra satelit menggunakan indikator yang disebut titik panas. Titik panas yang digunakan saat ini di Indonesia diperoleh dari pengolahan data citra satelit berorbit polar (MODIS dan VIIRS) dengan resolusi temporal yang rendah, yaitu hanya 6 kali dalam sehari. Tujuan dari penelitian ini adalah memanfaatkan data citra satelit Himawari-8 untuk deteksi kebakaran hutan dan lahan yang menghasilkan titik panas dengan resolusi temporal 10 menit, dimana hasilnya di validasi dengan citra polar dan data kebakaran lapangan. Lokasi penelitian berada di Provinsi Kalimantan Tengah dan waktu penelitian adalah bulan September 2019. Data yang digunakan untuk pengolahan adalah 5 saluran Advanced Himawari Imager, peta batas administrasi dan tutupan lahan. Pemrosesan data citra satelit mencakup pemilihan piksel penutup lahan dan batas administrasi, penentuan waktu pengamatan, eliminasi piksel awan, Algoritma Pemantau Kebakaran Aktif, dan validasi hasil. Data citra Himawari-8 dapat diolah menjadi titik panas dengan temporal 10 menit. Validasi terhadap citra polar memiliki tingkat akurasi 66,2\%-75,4\%, comission error 28,2-46,9\% dan omission error 24,6$33,8 \%$. Tingginya comision error terhadap citra VIIRS dikarenakan citra VIIRS memiliki resolusi spasial yang jauh lebih tinggi dibandingkan dengan citra Himawari-8.
\end{abstract}

Kata Kunci: Himawari-8, Kebakaran, Hotspot, MODIS, VIIRS.

\begin{abstract}
Forest and land fires occur almost every year in Indonesia, especially in Sumatra and Kalimantan during the dry season. Detection of forest and land fires with satellite imagery uses an indicator called a hotspot. The hotspots used today in Indonesia are obtained from the processing of polar orbital satellite image data (MODIS and VIIRS) with a low temporal resolution, which is only six times a day. The purpose of this study is to utilize Himawari-8 satellite imagery data for the detection of forest and land fires that produce hotspots with a temporal resolution of 10 minutes, where the results are validated with polar imagery and field fire data. The research location is in Central Kalimantan Province, and the time of the study is September 2019. Data used for processing are 5 Advanced Himawari Imager channels, administrative boundary maps, and land cover. Processing of satellite imagery data includes the selection of cover pixels and administrative boundaries, determination of observation time, elimination of cloud pixels, Active Fire Monitoring Algorithm, and validation of results. Himawari-8 image data can be processed into hotspots with a temporal 10 minutes. Validation of polar images has an accuracy rate of $66.2 \%-75.4 \%$, commission error $28.2-46.9 \%$ and omission error 24.6-33.8\%. The high commission error on the VIIRS image is because the VIIRS image has a much higher spatial resolution compared to the Himawari-8 image.
\end{abstract}

Keywords: Himawari-8, Fires, Hotspot, MODIS, VIIRS.

\section{PENDAhUluan}

Kebakaran hutan dan lahan terjadi hampir setiap tahun di Indonesia, terutama di wilayah Sumatera dan Kalimantan (Yulianti et al., 2013). Salah satu provinsi yang banyak mengalami kebakaran hutan dan lahan adalah Kalimantan
Tengah. Berdasarkan data Kementerian Lingkungan Hidup dan Kehutanan (KLHK, 2019) luas kebakaran hutan dan lahan tahun 2018 di Kalimantan Tengah mencapai 41.521,31 hektar, bahkan pada tahun 2015 luas kebakaran mencapai 583.833,44 hektar. 
Deteksi kebakaran menggunakan citra pengideraan jauh telah dilakukan pada akhir tahun 1970-an dan awal tahun 1980-an menggunakan citra Landsat (Milne, 1986) dan citra satelit NOAA AVHRR (Matson \& Dozier, 1981). Monitoring titik panas yang digunakan saat ini di Indonesia menggunakan satelit bertipe polar yaitu satelit Terra, Aqua dan Suomi NPP (LAPAN, 2016). Satelit Terra dan Aqua menggunakan sensor MODIS (Moderate Resolution Imaging Spectroradiometer) dan satelit Suomi NPP menggunakan sensor VIIRS (Visible Infrared Imaging Radiometer Suite) untuk deteksi kebakaran hutan dan lahan. Satelit Terra, Aqua dan Suomi NPP melakukan perekaman pada lokasi yang sama sebanyak 2 kali dalam satu hari, sehingga dalam satu hari ketiga satelit menghasilkan 6 data perekaman. Selain frekuensi observasi yang rendah, masalah lain adalah proses akuisisi hingga menjadi informasi titik panas memerlukan waktu 2-3 jam. Lamanya perolehan informasi titik panas merupakan kendala dalam penanggulangan kebakaran hutan dan lahan karena informasi yang terlambat dapat menyebabkan kebakaran hutan dan lahan semakin meluas dan sulit untuk dipadamkan.

Penelitian menggunakan citra satelit geostasioner pertama kali diteliti pada citra satelit GOES-8 tahun 1989 dan diaplikasikan tahun 1992 dengan nama Automated Biomass Burning Algorithm (ABBA) (Schmidt \& Prins, 2003) menggunakan saluran inframerah tengah dan inframerah yang telah umum digunakan saat ini. Satelit geostasiner yang telah diterapkan untuk mendeteksi kebakaran adalah seri satelit Geostationary Operational Environmental Satellite- $R$ (GOES-R) untuk wilayah Amerika, satelit Meteosat untuk wilayah Eropa dan Afrika dan MTSAT untuk sebagian besar wilayah Asia dan Australia. The Wildfire Automated Biomass Burning Algorithm (WF_ABBA) merupakan algoritma yang digunakan dalam mendeteksi kebakaran menggunakan satelit geostasioner. Titik panas yang dihasilkan dari citra satelit geostasioner dengan menggunakan metode WF_ABBA bila dibandingkan dengan titik panas dengan citra satelit MODIS, hasilnya secara umum akurasinya lebih rendah dari MODIS namun memiliki keunggulan, dimana lebih banyak kebakaran yang dapat dideteksi karena frekuensi observasi yang tinggi (Hyer et al., 2013). Pada perkembangannya WF_ABBA mengalami berbagi modifikasi misalkan AFMA (Active Fire Monitoring Algorithm) (Hassini et al., 2009) yang digunakan pada citra satelit Meteosat SEVIRI. AFMA memanfaatkan saluran inframerah tengah dan inframerah jauh sebagai saluran utama, serta dalam pengolahan menggunakan deviasi standar pada masing-masing saluran untuk mengurangi kesalahan deteksi.

Satelit Himawari-8 merupakan satelit generasi penerus dari satelit MTSAT-2 yang diluncurkan pada 7 Oktober 2014 dan beroperasi sejak 7 Juli 2015 (Bessho et al., 2016). Fatkhuroyan et al. (2017) melakukan penelitian dengan memanfaatkan citra satelit Himawari-8 untuk mendeteksi kebakaran hutan dan lahan di Kalimantan dan Sumatera menggunakan metode komposit RGB. Kebakaran hutan dan lahan diidentifikasi dari sebaran asap yang dihasilkan pada olahan citra dan dikonfirmasi dengan titik panas dari citra MODIS. Penelitian lain dilakukan oleh Fitriana et al. (2018) yang menggunakan pola spektral untuk mendeteksi kebakaran hutan dan lahan di pulau Sumatera, didapatkan citra satelit Himawari-8 memiliki kemampuan yang baik dalam deteksi kebakaran, ditunjukkan dengan pola yang jelas pada saluran 3 (inframerah dekat) dan 7 (inframerah tengah). Namun dua penelitian diatas belum menghasilkan titik panas. Oleh karena itu diperlukan kajian lebih lanjut terkait dengan deteksi kebakaran hutan dan lahan dengan menggunakan citra satelit Himawari-8, terutama di wilayah Kalimantan Tengah yang rawan terjadinya kebakaran hutan dan lahan.

Tujuan dari penelitian ini adalah memanfaatkan citra satelit geostasioner Himawari-8 Advanced Himawari Imager (AHI) yang memiliki resolusi temporal tinggi untuk deteksi kebakaran hutan dan lahan berupa titik panas dan menguji akurasinya.

\section{METODE}

\subsection{Lokasi Penelitian}

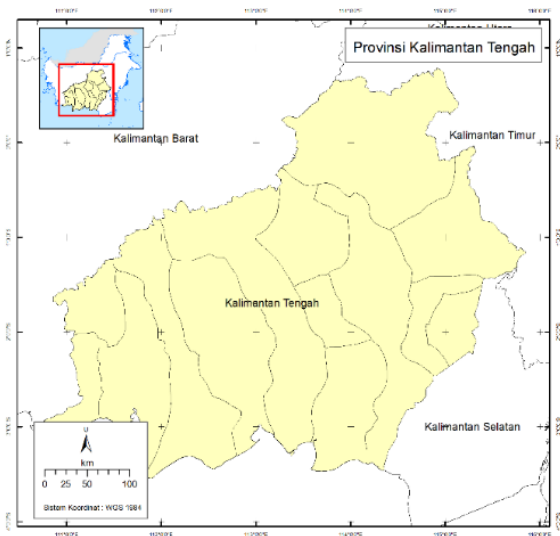

Gambar 1. Lokasi Penelitian

Lokasi penelitian dilakukan pada Provinsi Kalimantan. Secara geografis, Kalimantan terletak antara $0^{\circ} 45^{\prime}$ Lintang Utara, $3^{\circ} 30^{\prime}$ Lintang Selatan dan $111^{\circ}-116^{\circ}$ Bujur Timur. Provinsi Kalimantan Tengah merupakan provinsi terluas kedua di Indonesia memiliki luas wilayah mencapai $153.564 \mathrm{Km}^{2}$ dengan ibukota Palangka Raya. Wilayahnya terdiri dari Kawasan Hutan 12.675.364 $\mathrm{Ha}$ atau 82,16\% dan kawasan Non Kehutanan 2.751.416 $\mathrm{Ha}$ atau 17,84\%.

Dokumen Grand Design Pencegahan Kebakaran Hutan, Kebun dan Lahan yang dikeluarkan oleh Kementerian Koordinator Bidang Perekonomian, Kementerian Perencenaan Pembangunan Nasional/BAPPENAS dan 
Kementerian Lingkungan Hidup dan Kehutanan menyatakan Kalimantan Tengah merupakan salah satu provinsi yang rawan terhadap kebakaran hutan dan lahan, propinsi lainnya adalah Riau, Jambi, Sumatera Selatan, Kalimatan Barat, Kalimantan Timur, Kalimantan Selatan dan Kalimantan Utara.

\subsection{Data Penelitian}

Waktu penelitian kebakaran hutan dan lahan tahun 2019 berdasarkan jumlah titik panas MODIS dan VIIRS tertinggi yaitu bulan September. Data yang digunakan meliputi :

1. Citra Satelit Himawari-8 Advanced Himawari Imager dari Badan Meteorologi Klimatologi dan Geofisika (BMKG) yang merupakan instansi resmi pemerintah yang bekerja sama dengan Badan Meteorologi Jepang (JMA) dalam penyediaan data citra Himawari-8. Data citra Himawari-8 merupakan data utama dalam penelitian karena berguna untuk pengolahan citra yang menghasilkan titik panas. Data tersebut berformat SATAID (Satellite Animation and Interactive Diagnosis) yang telah terkoreksi radiometrik dan geometrik. Kajian ini menggunakan 5 saluran (band) dari 16 saluran (Japan Meteorological Agency, 2015) yang tersedia seperti disajikan pada Tabel 1.

2. Data titik panas MODIS dan VIIRS yang diperoleh dari laman FIRMS NASA (https://firms.modaps.eosdis.nasa.gov/downlo ad/) yang berisi koordinat lokasi, suhu kecerahan, waktu akusisi, jenis satelit, jenis sensor, tingkat kepercayaan, versi algoritma, suhu kecerahan pada saluran termal dan fire radiative power.

3. Citra MODIS dan VIIRS True Color untuk siang hari dan inframerah termal untuk malam hari yang diperoleh dari laman Earthdata NASA (https://worldview.earthdata.nasa.gov). Citra digunakan untuk melihat liputan awan dan sebaran asap.

4. Peta penutup lahan tahun 2011 provinsi Kalimantan Tengah skala $1: 5.000 .000$. Peta diperoleh dari Kementerian Lingkungan Hidup dan Kehutanan (KLHK).

5. Peta Rupa Bumi Indonesia (RBI) batas administrasi skala 1: 250.000 tahun 2015. Peta diperoleh dari Badan Informasi Geospasial (BIG).

Tabel 1. Saluran citra Himawari-8 yang digunakan dalam Pengolahan

\begin{tabular}{cccc}
\hline $\begin{array}{c}\text { Nomor } \\
\text { Saluran }\end{array}$ & Penamaan & $\begin{array}{c}\text { Panjang } \\
\text { Gelombang }\end{array}$ & $\begin{array}{c}\text { Resolusi } \\
\text { Spasial }\end{array}$ \\
\hline 3 & VS & $0,63-0,66$ & $0,5 \mathrm{~km}$ \\
4 & N1 & $0,85-0,87$ & $1 \mathrm{~km}$ \\
6 & N3 & $2,25-2,27$ & $2 \mathrm{~km}$ \\
7 & I4 & $3,74-3,96$ & $2 \mathrm{~km}$ \\
13 & IR & $10,3-10,6$ & $2 \mathrm{~km}$ \\
\hline
\end{tabular}

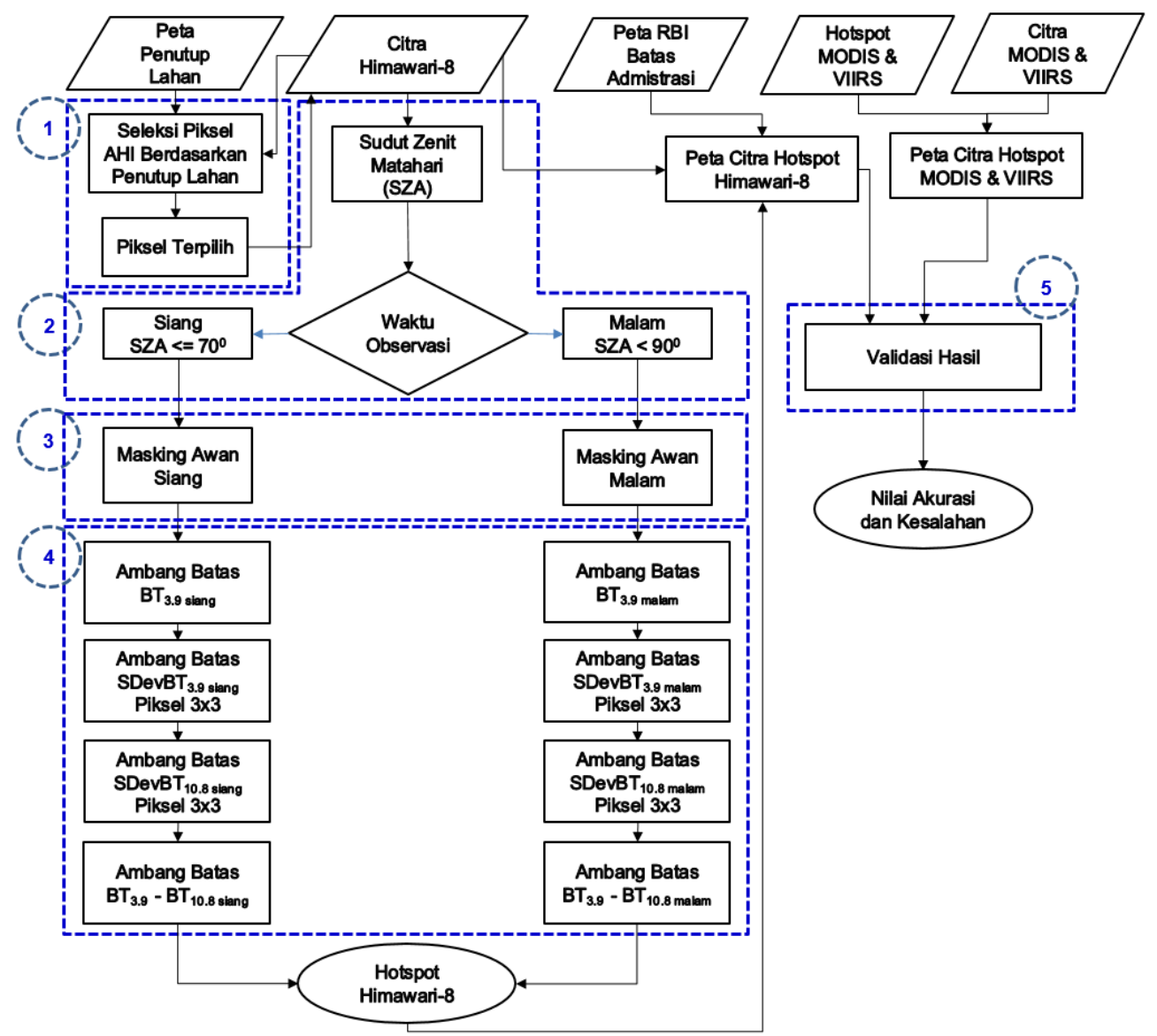

Gambar 2. Diagram alir penelitian 


\subsection{Cara Kerja}

Penelitian ini mengadopsi AFMA (Active Fire Monitoring Algorithm) (Hassini et al., 2009) untuk memperoleh titik panas dari satelit geostasioner. Metode AFMA memiliki kelemahan karena adanya peringatan palsu atau false alarm yang disebabkan dari anomali suhu urban dan pantulan pada air atau awan. Untuk itu diperlukan tambahan proses untuk memperbaiki hasilnya, yaitu dengan menggunakan peta penutup lahan. Penelitian ini terdiri dari 5 proses yaitu seleksi penutup lahan, penentuan waktu observasi, masking awan, active fire monitoring algorithm, validasi hasil seperti pada Gambar 2.

Perangkat lunak yang digunakan untuk pengolahan adalah bahasa program Python versi 2.7 yang berjalan pada sistem operasi Windows 10. Modul atau pustaka tambahan yang digunakan adalah Numpy untuk pengolahan data multidimensi, Matplotlib untuk pemetaan dan pembuatan grafik, Basemap untuk ekstensi peta dasar dari Matplotlib, OGR/GDAL untuk pengolahan data spasial dan Pandas untuk analisis data.

\subsubsection{Seleksi Penutup Lahan}

Langkah pertama adalah menyeleksi peta tutupan lahan pada area kajian. Jenis tutupan yang dipilih adalah hutan lahan kering primer, hutan lahan kering sekunder, hutan mangrove primer, hutan mangrove sekunder, hutan rawa primer, hutan rawa sekunder, hutan tanaman industri ( $\mathrm{HTI})$, perkebunan, permukiman, pertanian lahan kering, pertanian lahan kering bercampur dengan semak, rawa, savana, sawah, semak/belukar, rawa, tanah terbuka dan tambak, sedangkan tutupan lahan yang tidak dipilih adalah transmigrasi, tubuh air, tambak, pertambangan, awan. Jenis tutupan lahan terpilih untuk membedakan area yang merupakan area yang termasuk dalam kebakaran hutan dan lahan, serta untuk meminimalisir kesalahan deteksi pada tahap lainnya. Setelah mendapatkan tutupan lahan terpilih, dilakukan pemotongan area pada citra Himawari-8 dengan menggunakan peta tutupan lahan terpilih. Hasil pemotongan ini menghasilkan piksel citra Himawari-8 yang hanya pada area terpilih. Koordinat piksel terpilih disimpan dalam file agar dapat digunakan untuk pengolahan citra Himawari-8 secara multitemporal pada proses berikutnya.

\subsubsection{Penentuan Waktu Observasi}

Satu citra Himawari-8 memiliki waktu observasinya berbeda, dimana perbedaan waktu observasi akan membedakan nilai ambang batas pada proses berikutnya. Waktu observasi dibagi menjadi 3 , yaitu siang, malam dan peralihan. Perbedaan observasi siang dan malam hari berdasarkan sudut zenit matahari atau solar zenith angle (SZA) seperti pada Gambar 3, sudut zenit matahari kurang dari sama dengan $70^{\circ}$ menyatakan waktu observasi pada piksel adalah siang hari, SZA lebih besar sama dengan $90^{\circ}$ berarti pada waktu malam hari, sedangkan SZA antara $70^{\circ}$ hingga $90^{\circ}$ berarti waktu observasi peralihan antara siang dan malam hari atau sebaliknya. Sudut zenit matahari $(\theta)$ dihitung berdasarkan tanggal, waktu dan koordinat (lintang) piksel (NOAA, n.d.). Untuk menghitung SZA digunakan persamaan berikut:

$$
\begin{aligned}
& \cos \theta=\sin \varphi \sin \delta+\cos \varphi \cos h \\
& \delta=-23,45 \cos \left(\frac{2 \pi J}{365}+\frac{20 \pi}{365}\right) \\
& h=-\frac{t-12}{12} \\
& t=h h+\frac{m m}{60}+\frac{s s}{3600}
\end{aligned}
$$

$$
\begin{array}{ll}
\text { dengan: } \\
\varphi \quad=\text { lintang }\left(^{0}\right) \\
\delta \quad=\text { sudut deklinasi matahari }\left(^{0}\right) \\
\mathrm{J} & =\text { tanggal julian } \\
\mathrm{h} & =\text { sudut waktu }\left({ }^{0}\right) \\
\mathrm{t} & =\text { fraksi waktu (dalam UTC) } \\
\mathrm{hh} & =\text { jam } \\
\mathrm{mm} & =\text { menit } \\
\mathrm{ss} & =\text { detik }
\end{array}
$$

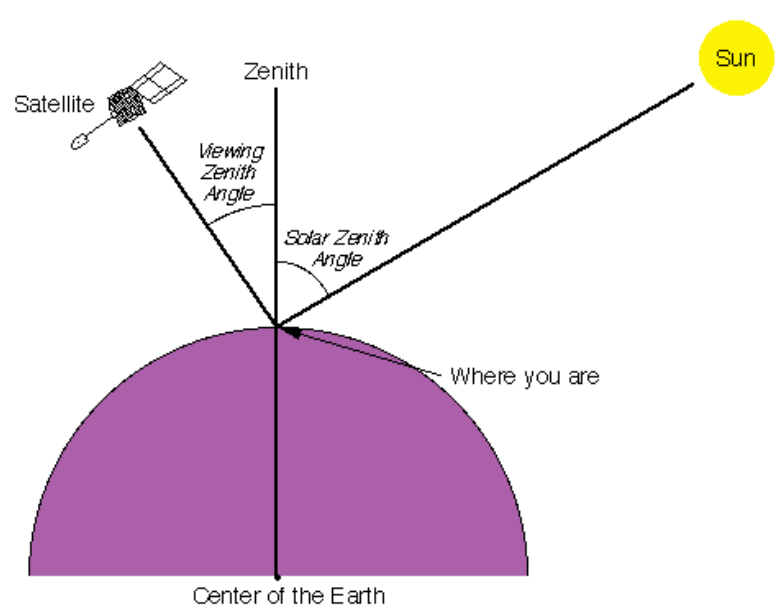

Gambar 3. Ilustrasi sudut zenit matahari. (Sumber: Mackay (n.d))

\subsubsection{Masking Awan}

Setelah mendapatkan piksel penutup lahan terpilih dan penentuan waktu observasi, langkah selanjutnya adalah masking awan. Masking awan berguna untuk menghilangkan piksel awan pada citra yang akan diproses. Proses ini mengadopsi metode yang digunakan pada citra MODIS (Giglio et al., 2016), dengan persamaan :

\section{a. Kondisi siang hari}

$R_{v s}+R_{N 1}>0.9$ atau

$B T_{I R}<265^{\circ} \mathrm{K}$ atau

$R_{V s}+R_{N 1}>0.7$ dan $B T_{I R}<285^{\circ} \mathrm{K}$ 
dengan :

Rvs = reflektansi saluran VS

$\mathrm{R}_{\mathrm{N} 1} \quad=$ reflektansi saluran $\mathrm{N} 1$

$\mathrm{BT}_{\mathrm{IR}}=$ suhu kecerahan saluran IR (Kelvin)

b. Kondisi malam hari

$B T_{I R}<265^{\circ} \mathrm{K}$

\subsubsection{Active \\ Fire \\ Algorithm \\ Monitoring \\ Proses selanjutnya adalah mengidentifikasi} piksel yang berpotensi sebagai titik panas. Terdapat perbedaan nilai ambang batas pada kondisi siang, malam dan peralihan. Perbedaan waktu observasi berdasarkan sudut zenit matahari atau solar zenith angle (SZA). Perbedaan waktu observasi berpengaruh pada nilai ambang batas, misalkan untuk siang hari suhu kecerahan saluran IR $\left(\mathrm{BT}_{14}\right)$ yang berpotensi kebakaran adalah lebih besar dari $315^{\circ} \mathrm{K}$, sedangkan untuk malam hari $\mathrm{BT}_{14}$ lebih besar dari $290^{\circ} \mathrm{K}$.

Perbedaan nilai ambang batas ini disebabkan perbedaan sumber energi yang diterima objek, pada siang hari suhu kecerahan objek berasal dari energi radiasi matahari dan bumi, sedangkan pada malam hari hanya dari emisi permukaan bumi. Persaamaan untuk siang hari sebagai berikut :

$$
\begin{aligned}
& \mathrm{BT}_{14}>315^{0} \mathrm{~K} \\
& \text { SdevBT }_{14}>4^{0} \mathrm{~K} \\
& \text { SdevBT }_{I R}>2^{0} \mathrm{~K} \\
& \mathrm{BT}_{14}-\mathrm{BT}_{\mathrm{IR}}>10^{\circ} \mathrm{K}
\end{aligned}
$$

dimana:

SdevBT $_{14}=$ deviasi standar $3 \times 3$ piksel sekitarnya pada saluran 14 (Kelvin)

SdevBT IR = deviasi standar $3 \times 3$ piksel sekitarnya pada saluran IR (Kelvin)

Nilai ambang batas pada persamaan (7) sampai dengan (10) berlaku untuk siang hari, jika malam hari ambang batasnya masing-masing adalah 290, 4, 2 dan 5.

Penentuan nilai ambang batas pada waktu observasi peralihan menggunakan interpolasi antara SZA siang dan SZA malam dengan nilai ambang batas masing-masing. Penentuan nilai ambang batas peralihan adalah :

$$
B T t=B T m-\frac{S Z A m-S Z A t}{S Z A m-S Z A S} *(B T m-B T s)
$$

dengan :

$B T t=$ suhu kecerahan pada waktu observasi peralihan

$B T m$ = nilai ambang batas suhu kecerahan malam hari, bernilai $290^{\circ} \mathrm{K}$

$B T s=$ nilai ambang batas suhu kecerahan siang hari, bernilai $315^{\circ} \mathrm{K}$
$S Z A m$ = sudut zenit matahari malam hari, bernilai $90^{\circ}$

$S Z A s$ = sudut zenit matahari malam hari, bernilai $70^{\circ}$

Proses 2.3.2 hingga 2.3.4 menghasilkan titik panas, dimana koordinat titik panas merupakan titik tengah dari piksel yang diidentifikasi sebagai kebakaran hutan dan lahan. Ilustrasi dari perbandingan lokasi titik panas dengan kebakaran di lapangan disajikan pada Gambar 4.
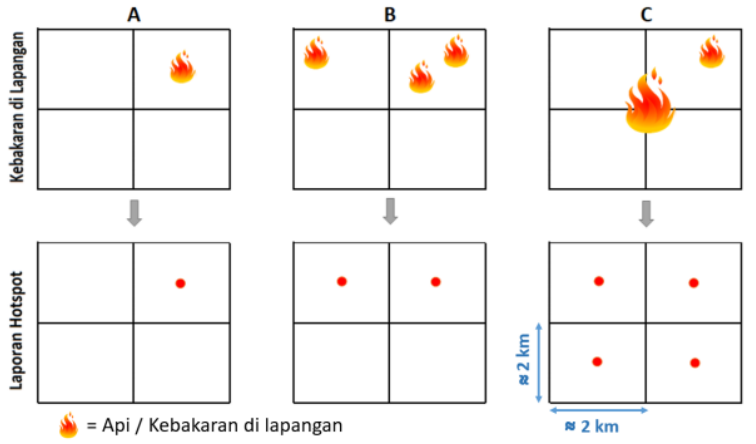

- = Koordinat hotspot (lintang \& bujur) dari titik tengah piksel

Gambar 4. Ilustrasi penentuan koordinat hotspot Himawari-8.

(sumber: Modifikasi dari FIRMS NASA, 2019)

Lokasi kebakaran tidak selalu tepat dengan koordinat hotspot seperti pada Gambar 4 . Terdapat 3 contoh, pertama sebuah kebakaran terjadi pada titik tengah piksel, maka koordinat piksel sama dengan lokasi kebakaran. Contoh kedua, kebakaran lebih dari satu lokasi dan kebakaran tidak tepat berada di tengah piksel, maka koordinat piksel tetap berada pada titik tengah piksel. Contoh ketiga, kebakaran besar terjadi pada persimpangan piksel, maka koordinat piksel adalah pada masing - masing titik tengah piksel yang bersinggungan.

Titik panas ditumpang-susun dengan citra RGB komposit asap, metode RGB komposit berdasarkan kajian yang dilakukan oleh Fatkhuroyan et al. (2017) yang dilakukan dalam deteksi kebakaran hutan dan lahan di Pulau Sumatera dan Kalimantan. RGB asap menggunakan 3 kanal yaitu VS (merah), N1 (hijau) dan N3 (biru). Asap terlihat dengan penampakan visual berwarna kecokelatan. Kombinasi titik panas dan sebaran asap dapat mengkonfirmasi bahwa suatu area mengalami kebakaran.

\subsubsection{Validasi Hasil}

Titik panas Himawari-8 dengan resolusi spasial $2 \mathrm{~km}$ divalidasi dengan titik panas MODIS dan VIIRS yang memiliki resolusi spasial yang lebih tinggi yaitu masing-masing $1 \mathrm{~km}$ dan 375 meter. Akurasi dan kesalahan titik panas yang dihasilkan dari pengolahan citra Himawari-8 diperoleh dengan membandingkan dengan titik panas dari citra MODIS dan VIIRS pada waktu akuisi yang sama atau berdekatan. Teknik validasi 
antar satelit yang digunakan mengacu pada kajian yang dilakukan oleh Wickramasinghe et al. (2018) dengan persamaan :

$$
d=\left(L E O_{d d}+A H I_{d d}\right) / 2+500
$$

dimana d adalah maksimum jarak titik antara titik tengah piksel citra MODIS/VIIRS dengan AHI (dalam meter), $L E O_{d d}$ adalah panjang diagonal piksel citra MODIS/VIIRS, $A H I_{d d}$ adalah panjang diagonal piksel citra Himawari-8 dan 500 panjang maksimum penyangga/buffer citra Himawari-8.

Untuk mengukur tingkat akurasi dan kesalahan digunakan tabel error matrix seperti metode yang digunakan oleh Manyangadze (2009) seperti berikut.

Tabel 2. Error Matrix

\begin{tabular}{|c|c|c|c|c|}
\hline \multicolumn{2}{|c|}{ Hotspot } & \multicolumn{3}{c|}{ MODIS atau VIIRS } \\
\cline { 3 - 5 } & $\mathrm{Y}$ & $\mathrm{N}$ & Total \\
\hline \multirow{3}{*}{ Himawari-8 } & $\mathrm{Y}$ & & & \\
\cline { 2 - 5 } & Total & & & \\
\cline { 2 - 5 } & & & & \\
\hline
\end{tabular}

Tabel 2 akan menghasilkan tingkat akurasi berupa Percentage Correct (PC), Comission Error (CE) dimana terdapat hotspot Himawari-8 tetapi tidak ada hotspot MODIS/VIIRS dan Omission Error dimana terdapat hotspot MODIS/VIIRS namun tidak terdapat titik panas Himawari-8.

\section{HASIL DAN PEMBAHASAN}

Citra Himawari-8 diolah pada rentang bulan September 2019. Pada bahasan dibawah diberikan contoh untuk kasus tanggal 5 September 2019 pukul 05.20 UTC untuk kasus siang hari yang disesuaikan dengan waktu akuisisi citra VIIRS di wilayah Kalimantan Tengah. Kesesuaian waktu akuisisi citra Himawari-8 dengan citra VIIRS untuk keperluan validasi pada tahap akhir.

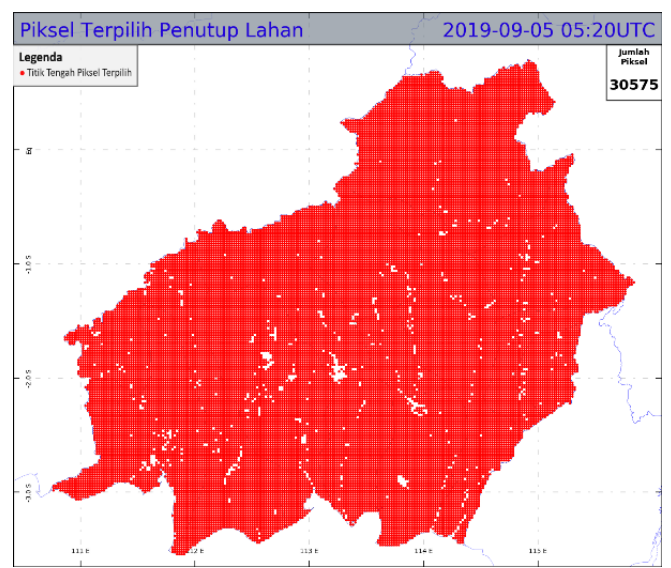

Gambar 5. Piksel terpilih untuk penutup lahan.
Wilayah Kalimantan Tengah berdasarkan citra Himawari-8 dengan resolusi spasial memiliki 31.207 piksel. Hasil seleksi piksel berdasarkan penutup lahan didapakan 30.575 piksel seperti tersaji pada Gambar 5. Terdapat 632 piksel yang tereliminasi.

Penentuan waktu observasi pada tanggal 5 September 2019 pukul 05.20 UTC menunjukkan semua piksel berada pada kondisi siang hari seperti tersaji pada Gambar 6 . Nilai sudut zenit matahari kurang dari $70^{\circ}$ yaitu pada rentang $10^{\circ}-20^{\circ}$, sehingga pada proses berikutnya semua piksel diproses menggunakan nilai ambang batas untuk siang hari.

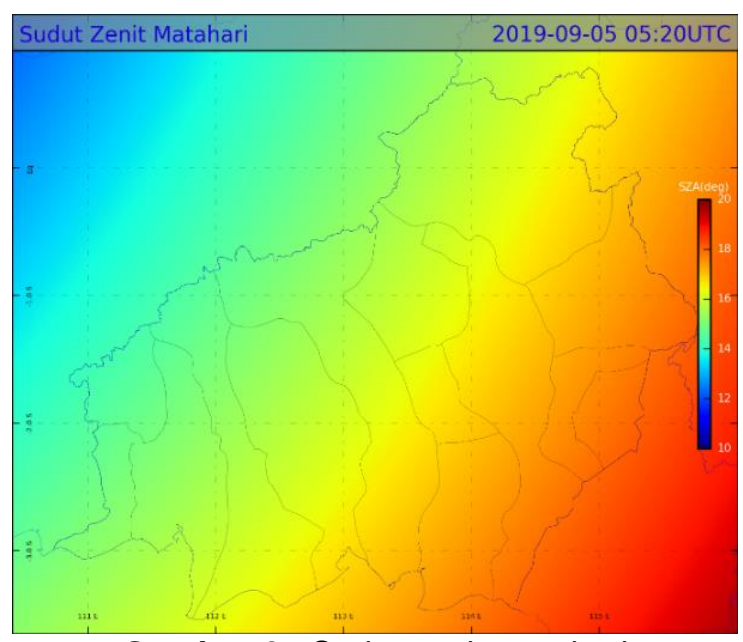

Gambar 6. Sudut zenit matahari

Hasil pengolahan masking awan (Gambar 7) terdapat 310 piksel awan, sehingga terdapat 30.265 piksel terpilih pada proses ini. Namun demikian nilai 310 merupakan piksel awan setelah proses seleksi penutup awan, sehingga memungkinkan terdapat piksel awan yang berada pada piksel penutup lahan yang tidak terpilih. Pada citra saluran Inframerah jauh (IR) terlihat pada sebagian kecil area berwarna putih dengan suhu kurang dari $265^{\circ}$ Kelvin yang mengindikasikan pada area tersebut tertutup awan.

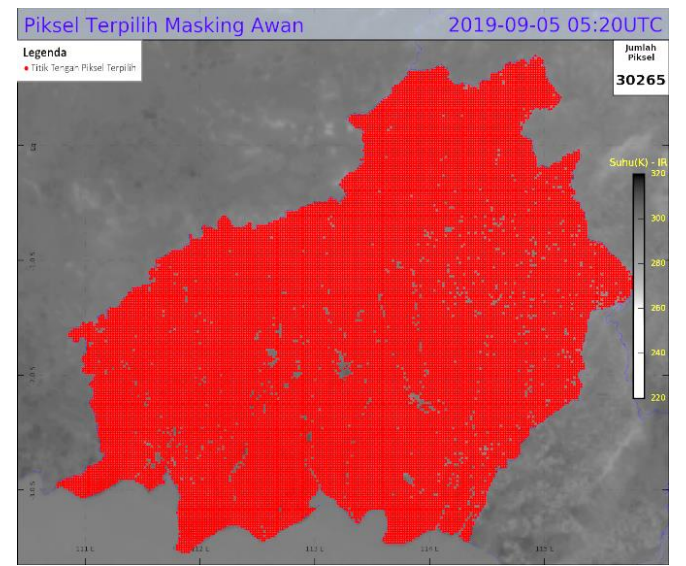

Gambar 7. Piksel terpilih untuk masking awan. 


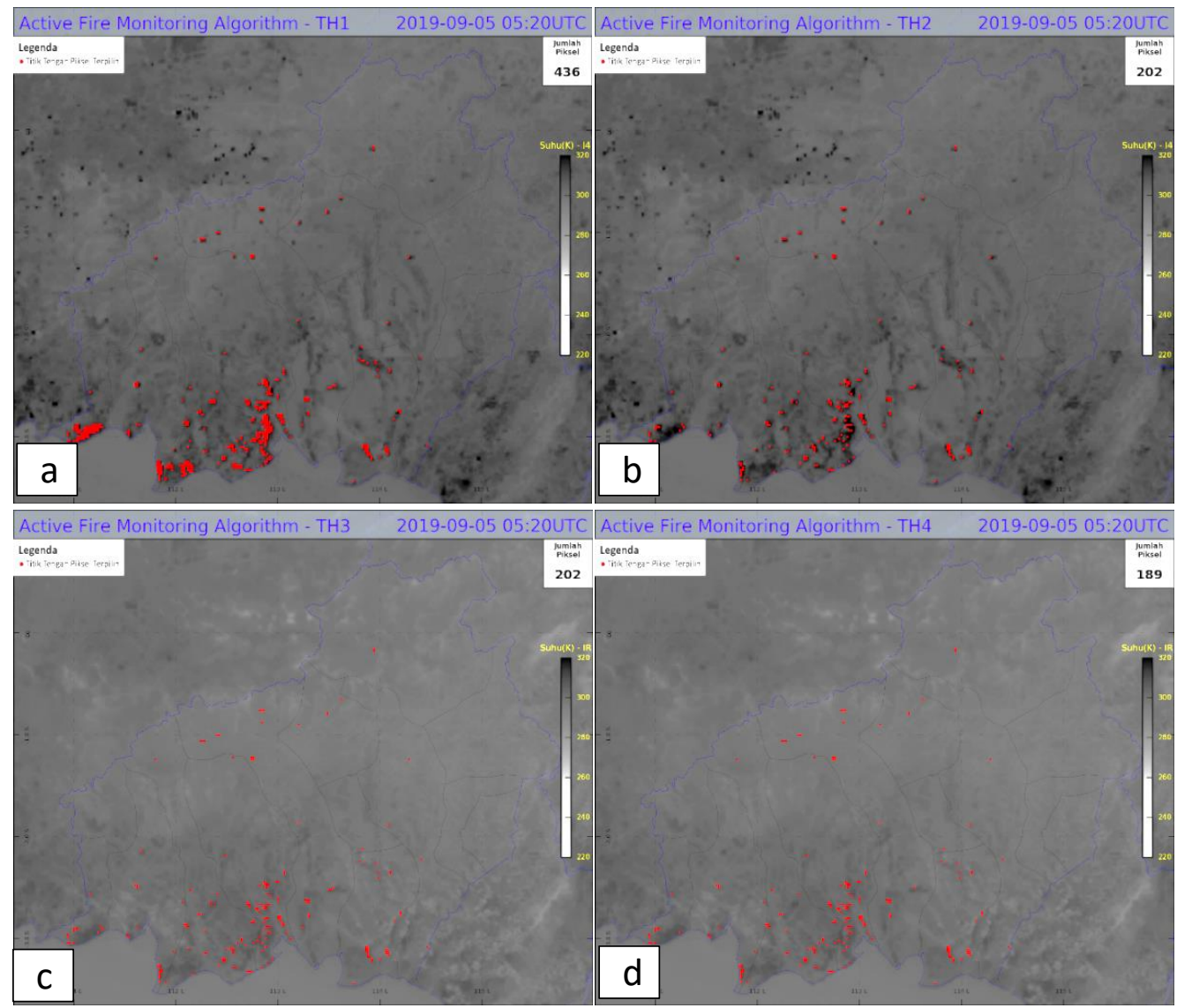

Gambar 8. Seleksi piksel proses AFMA (a) tahap 1, (b) tahap 2, (c) tahap 3, dan (d) tahap 4.

Tabel 3. Hasil Overlay Titik Panas dan Batas Administrasi.

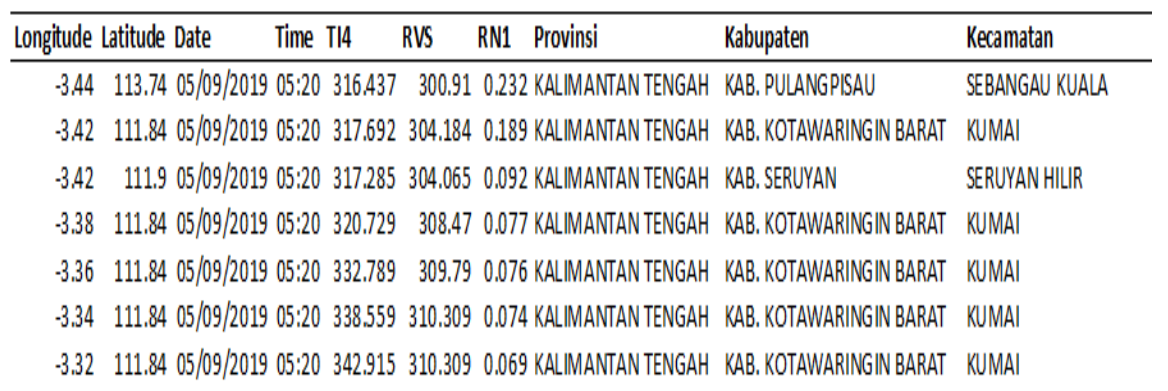

AFMA memiliki 4 tahap (Gambar 8) berdasarkan nilai ambang batas. Pada tahap pertama (Gambar 8.a) mendapatkan 436 piksel, yang berarti dari 30.265 piksel proses sebelumnya hanya 436 piksel yang memiliki nilai lebih dari $315^{\circ}$ Kelvin pada saluran inframerah tengah (14). Tahap kedua (Gambar 8.b) menghasilkan 202 piksel terpilih, yang berarti piksel citra inframerah tengah pada masing-masing pikselnya terhadap piksel sekitar ( $3 \times 3$ piksel) deviasi standarnya yang lebih besar dari $4^{0}$ Kelvin sebanyak 234 piksel. Tahap ketiga (Gambar 8.c) menghasilkan 202 piksel terpilih, artinya piksel citra inframerah jauh pada masing-masing pikselnya terhadap piksel sekitar ( $3 \times 3$ piksel) deviasi standarnya yang lebih besar dari $2^{\circ}$ Kelvin adalah 0 piksel. Nilai 0 berarti tidak terdapat eliminasi piksel, karena tidak ada syarat piksel yang memenuhi. Tahap keempat menghasilkan 189 piksel, berarti terdapat 45 piksel yang tereliminasi pada proses selisih inframerah jauh dan inframerah tengah yang lebih besar dari $10^{\circ}$ Kelvin.

Piksel terpilih pada proses akhir (Gambar 8.d) adalah 189 , nilai ini menunjukkan titik panas yang dihasilkan adalah 189 titik. Kemudian titik panas ini ditumpang susun (overlay) dengan peta batas administrasi hingga tingkat kecamatan. Tujuan dari proses ini adalah untuk memudahkan dalam identifikasi lokasi titik panas. Contoh hasil dari proses overlay seperti yang disajikan pada Tabel 3.

Tabel berisi koordinat lokasi, waktu, jam, suhu kecerahan saluran inframerah tengah (TI4), reflektansi saluran visibel (RVS), reflektansi saluran inframerah dekat-1 (RN1), provinsi, kabupaten dan kecamatan. Berdasarkan batas administrasi didapatkan titik panas tertinggi berada di Kabupaten Kotawaringin Timur sebanyak 60 titik dan Kabupaten Seruyan 35 titik. 


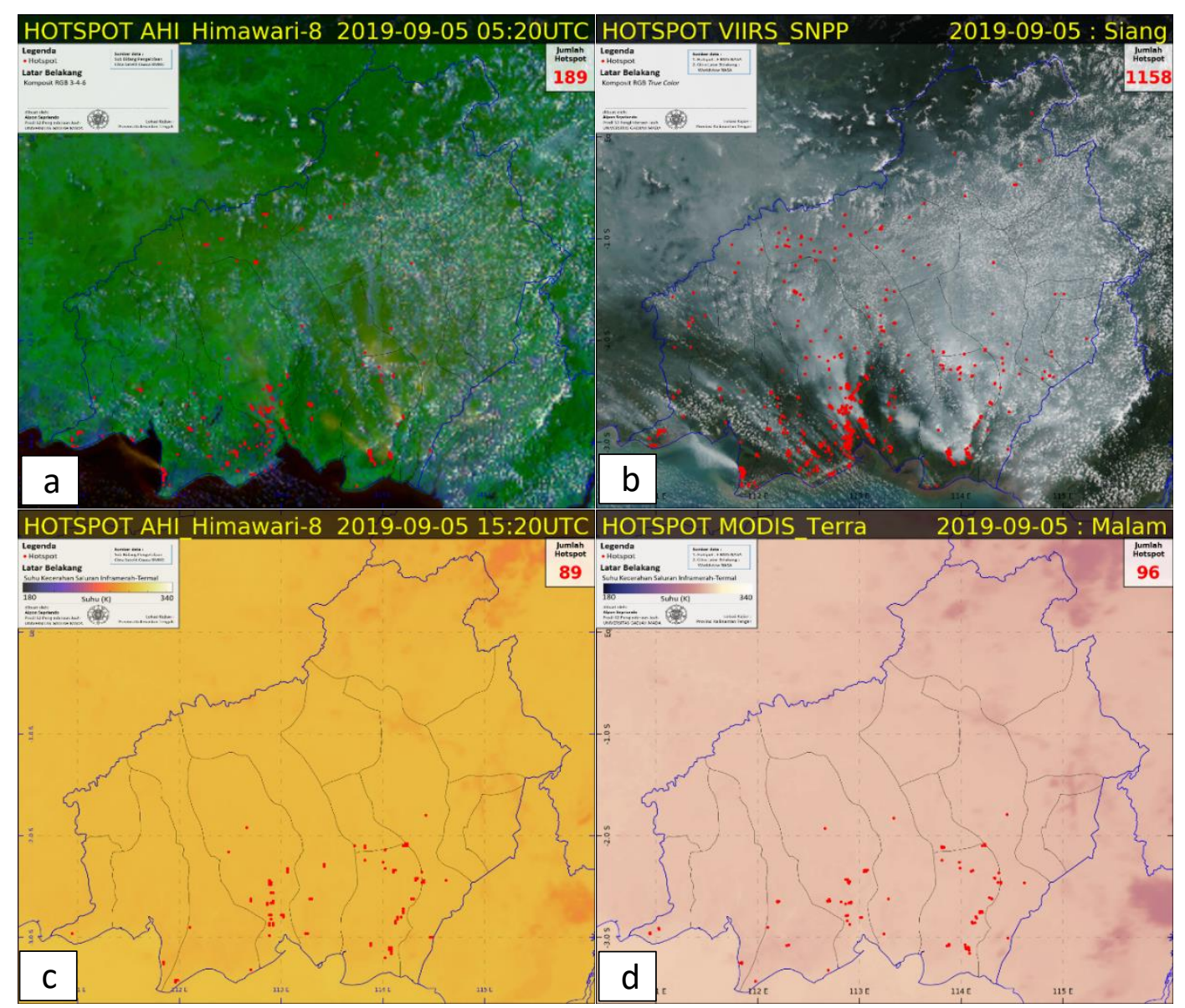

Gambar 9. Titik PANAS citra (a) Himawari-8 siang, (b) VIIRS siang, (c) Himawari-8 malam, dan (d) MODIS malam.

Titik panas yang dihasilkan juga ditumpang susun dengan citra komposit RBG 3-4-6 untuk melihat liputan awan, daerah bervegetasi dan sebaran asap seperti pada Gambar 9.a. Interpretasi citra komposit liputan awan berwarna putih, vegetasi berwarna hijau dan asap berwarna cokelat. Pada citra yang ditumpang susun dengan titik panas terlihat bahwa terdapat titik panas yang disertai dengan sebaran asap disekitarnya di Kabupaten Kotawaringin Barat bagian selatan, kondisi ini mengkonfirmasi di daerah tersebut terjadi kebakaran hutan dan lahan. Contoh lain dari adanya titik panas dan asap berada di Kabupaten Pulang Pisau bagian selatan, dimana asapnya menyebar hingga ke Kabupaten Katingan.

Langkah selanjutnya titik panas dan citra komposit RGB 3-4-6 Himawari-8 dibandingan dengan titik panas dan citra true color VIIRS (Gambar 9.b) pada waktu akuisisi yang hampir sama. Secara analisis visual, terlihat kesamaan pola sebaran titik panas dari kedua citra, namun terdapat perbedaan jumlah titik panas. Titik panas
VIIRS berjumlah 1.158 titik, jumlahnya jauh lebih banyak dibandingkan dengan titik panas Himawari-8 yang hanya berjumlah 189 titik. Perbedaan jumlah titik panas disebabkan oleh perbedaan resolusi spasial, citra Himawari-8 memiliki resolusi spasial $2 \mathrm{~km}$ sedangkan citra VIIRS memiliki resolusi spasial 375 meter. Semakin besar resolusi spasial, semakin baik citra satelit dalam identifikasi objek. Kebakaran dengan luasan lebih kecil dapat diidentifikasi dengan citra VIIRS dibandingkan citra Himawari-8.

Contoh lain untuk deteksi kebakaran hutan dan lahan adalah untuk kasus malam hari yaitu pukul 15.20 UTC tanggal 5 September 2019. Sebaran asap tidak dapat dideteksi dengan citra satelit Himawari-8 pada malam hari karena identifikasi sebaran asap memerlukan nilai reflektansi dari saluran visibel dan inframerah dekat. Sebagai pengganti, digunakan saluran inframerah jauh untuk melihat liputan awan pada malam hari. Citra Himawari-8 mendeteksi 89 titik panas (Gambar 9.c) sedangkan citra MODIS mendeteksi sebanyak 96 titik panas Gambar (9.d). 


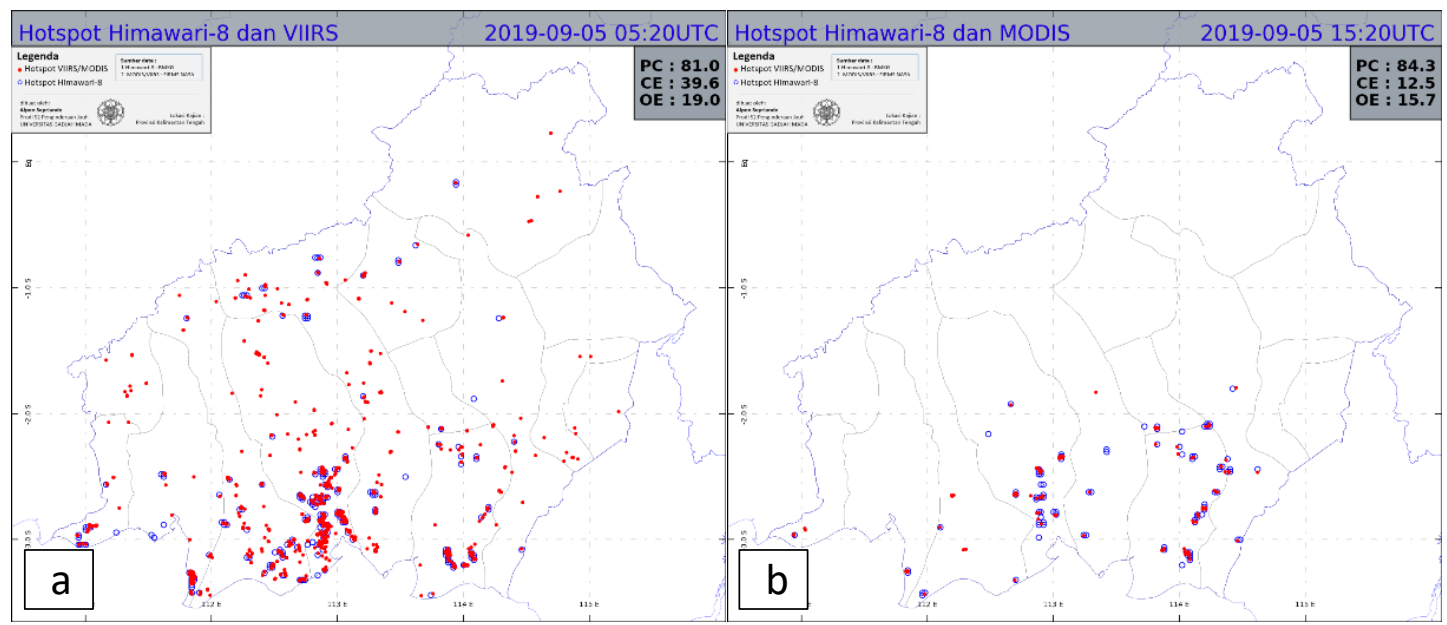

Gambar 10. Peta validasi titik panas Himawari-8 terhadap (a) VIIRS-siang dan (b) MODIS-malam.

Langkah terakhir pengolahan citra Himawari-8 menjadi titik panas adalah adalah validasi titik panas Himawari-8 terhadap titik panas VIIRS dan MODIS. Pada Gambar 10.a terlihat bahwa tingkat akurasi (percentage correct) titik panas Himawari-8 terhadap VIIRS untuk kasus siang hari adalah $81 \%$, sedangkan tingkat kesalahannya untuk commission error $39.6 \%$ dan omission error $19 \%$. Tingkat akurasi titik panas Himawari-8 terhadap MODIS untuk kasus malam hari adalah $84,3 \%$, sedangkan tingkat kesalahannya untuk commission error $12,5 \%$ dan omission error $15,7 \%$.

Setelah mendapatkan titik panas Himawari8 dan validasinya untuk dua contoh kasus, selanjutnya dilakukan pembuatan titik panas dalam rentang waktu 1 hari dengan temporal 10 menit. Kondisi ideal frekuensi data berjumlah 144, namun terdapat kendala kelengkapan data, sehingga hanya dihasilkan 139 data titik panas seperti pada Gambar 11. Pola umum jumlah titik panas adalah naik dari pukul 00.00 UTC dan mencapai puncaknya pukul 06.20 UTC sebanyak 227 titik, kemudian turun hingga pukul 09.00 UTC menjadi 98 titik, kemudian kembali naik dengan puncak tertinggi kedua pukul 10.10 UTC sebanyak 184 titik. Setelah itu, titik panas terus menurun hingga pukul 23.50 UTC dengan jumlah titik panas 12 titik.

Data yang diproses selama bulan September 2019 seperti yang tersaji pada Gambar 12 menunjukkan bahwa tingkat akurasi dan kesalahan titik panas Himawari-8 terhadap titik panas MODIS dan VIIRS bervariasi dengan jumlah titik panas yang dihasilkan berjumlah 11.290 titik. Jumlah titik panas yang sesuai dengan titik panas MODIS dan VIIRS berjumlah 7905 titik. Titik panas Himawari-8 terhadap titik panas MODIS memiliki tingkat akurasi (percentage correct/PC) $66,2 \%$ dan tingkat kesalahan untuk commission error (CO) 28,2\% dan omission error (OE) 33,8\%. Titik panas Himawari-8 terhadap titik panas VIIRS memiliki akurasi $75,4 \%$, sedangkan tingkat kesalahan untuk commission error $46,9 \%$ dan omission error $24,6 \%$. Tingkat akurasi titik panas Himawari-8 terhadap VIIRS lebih baik dibandingkan dengan titik panas Himawari-8 terhadap MODIS, namun tingkat kesalahan titik panas Himawari-8 terhadap MODIS lebih kecil dibandingkan dengan titik panas terhadap VIIRS.

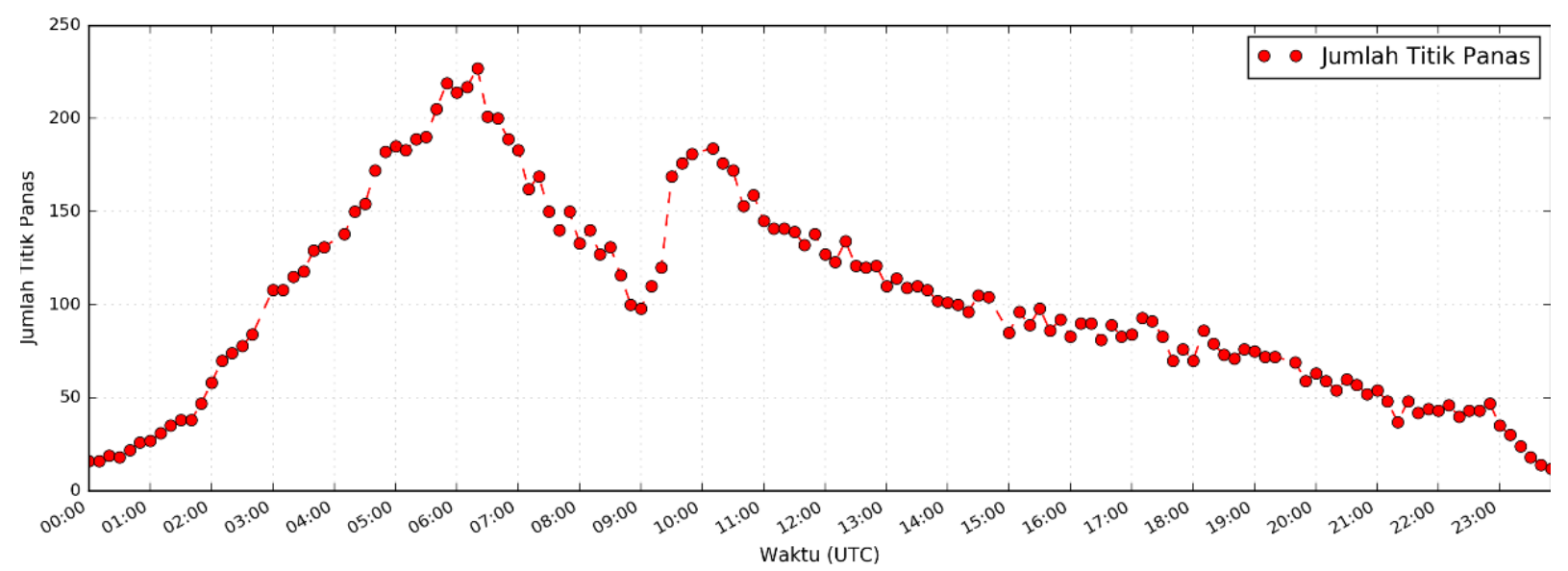

Gambar 11. Jumlah titik panas Himawari-8 tanggal 5 September 2019 temporal 10 menit. 

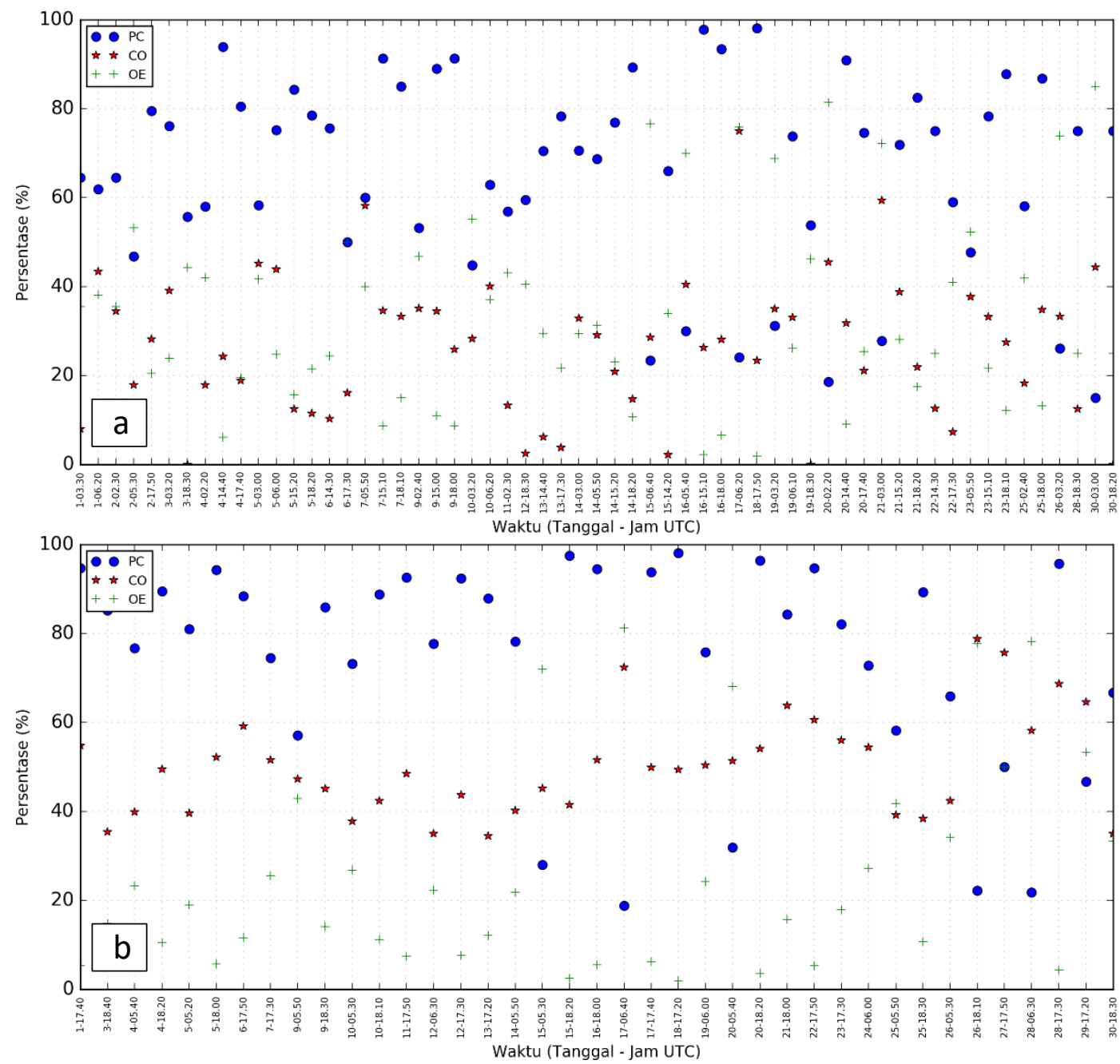

Gambar 12. Validasi titik panas Himawari-8 bulan September 2019 terhadap titik panas (a) MODIS dan (b) VIIRS.

\section{KESIMPULAN}

Dari uraian diatas dapat ditarik kesimpulan sebagai berikut:

1. Citra Himawari-8 dapat diolah menjadi titik panas (hotspot) untuk identifikasi kebakaran hutan dan lahan dengan resolusi spasial $2 \mathrm{~km}$ dan resolusi temporal 10 menit.

2. Validasi titik panas Himawari-8 terhadap titik panas MODIS dan VIIRS mendapatkan tingkat akurasi $66,2 \%$ terhadap MODIS dan $75,4 \%$ terhadap VIIRS. Nilai commission error terhadap titik panas MODIS adalah $28,2 \%$ dan omission error 33,8\%, sedangkan nilai commission error terhadap titik panas VIIRS adalah $46,9 \%$ dan omission error $24,6 \%$. Tingginya commission error terhadap titik panas VIIRS dikarenakan citra VIIRS memliliki resolusi spasial yang jauh lebih tinggi dibandingkan dengan citra Himawari-8.

\section{DAFTAR PUSTAKA}

Bessho, K., Date, K., Hayashi, M., Ikeda, A., Imai, T., Inoue, H., Kumagai, Y., Miyakawa, T., Murata, H., Ohno, T., Okuyama, A., Oyama, R., Sasaki, Y., Shimazu, Y., Shimoji, K.,
Sumida, Y., Suzuki, M., Taniguchi, H., Tsuchiyama, H. Uesawa, D., Yokota, H., Yoshida, R. (2016). An Introduction to Himawari-8/9 Japans New-Generation Geostationary Meteorological Satellites. Journal of the Meteorological Society of Japan. Ser. II, 94(2), 151-183. doi: 10.2151/jmsj.2016-009

Fatkhuroyan., Wati, T., Panjaitan, A. (2017). Forest Fires Detection in Indonesia Using Satellite Himawari-8 (Case Study: Sumatera and Kalimantan on August-October 2015). IOP Conference Series: Earth and Environmental Science, 54, 012053. doi: 10.1088/1755-1315/54/1/012053

Fitriana, H.L., Sulma, S., Zubaidah, A., Suwarsono., Prasasti, I. (2018). Spectral Analysis of the Himawari-8 Data for Hotspot Detection from Land/Forest Fires in Sumatra. International Journal of Remote Sensing and Earth Sciences, 15(1), 15-28. doi: 10.30536/j.ijreses.2018.v15.a2836

Giglio, L., Schroeder, W., Justice, C.O. (2016). The Collection 6 MODIS Active Fire Detection Algorithm and Fire Products. Remote Sensing of Environment, 178, 3141. doi: 10.1016/j.rse.2016.02.054 
Hassini, A., Benabdelouahed, F., Noureddine, B., Belbachir, A.H. (2009). Active Fire Monitoring with Level 1.5 MSG Satellite Images. American Journal of Applied Sciences, 6(1), 157-166. doi: 10.3844/ajas.2009.157.166

Hyer, E.J., Reid, J.S., Prins, E.M., Hoffman, J.P., Schmidt, C.C., Miettinen, J.I., Giglio, L. (2013). Patterns of Fire Activity over Indonesia and Malaysia from Polar and Geostationary Satellite Observations. Atmospheric Research, 122, 504-519. doi: 10.1016/j.atmosres.2012.06.011

Japan Meteorological Agency. (2015). Himawari Standard Data User's Guide.

Lembaga Penerbangan dan Antariksa Nasional. (2016). Panduan Teknis (V.01) Informasi Titik Panas (Hotspot) Kebakaran Hutan/Lahan (Vol. 01). Indonesia.

Manyangadze, T. (2009). Forest Fire Detection for Near Real-Time Monitoring Using Geostationary Satellites. Thesis. International Institute for Geo-Information Science and Earth Observation.

Matson, M., Dozier, J. (1981). Identification of Subresolution High Temperature Sources Using a Thermal IR Sensor. Photogrammetric Engineering and Remote Sensing, 47(2), 1311-1318.
Milne, A.K. (1986). The Use of Remote Sensing in Mapping and Monitoring Vegetational Change Associated with Bushfire Events in Eastern Australia. Geocarto International, 1(1), 25-32. doi: 10.1080/10106048609354022

NOAA. (n.d.). Calculating zenith and azimuth angles for GridSat-B1. https://www.ncdc.noaa.gov/gridsat/docs/An gle_Calculations.pdf

Schmidt, C.C., Prins, E.M. (2003). GOES Wildfire ABBA applications in the Western Hemisphere. 2nd International Wildland Fire Ecology and Fire Management Congress, AMS 5th Symposium Fire and Forest Meteorology, (November), 4.

Wickramasinghe, C., Wallace, L., Reinke, K., Jones, S. (2018). Intercomparison of Himawari-8 AHI-FSA with MODIS and VIIRS Active Fire Products. International Journal of Digital Earth. doi: 10.1080/17538947.2018.1527402

Yulianti, N., Hayasaka, H., Sepriando, A. (2013). Recent Trends of Fire Occurrence in Sumatra (Analysis Using MODIS Hotspot Data): A Comparison with Fire Occurrence in Kalimantan. Open Journal of Forestry, 3(4), 129-137. doi: 10.4236/ojf.2013.34021 